\title{
Parent-Adolescent Relations in Changing Societies: A Cross-Cultural Study
}

\author{
Gisela Trommsdorff
}

\section{Introduction}

The present study of social change and adolescent development is committed to a contextual approach. Contextual approaches emphasize the multilevel bases of human action and individual development and their interrelations on all levels. A key notion of the contextual viewpoint is that individual development is interconnected with the environment and that they interact reciprocally. Individual development is seen as a complex system in which biological, emotional, cognitive, and social elements interact with each other while simultaneously interacting with the changing environment (cf., Bronfenbrenner, 1979; Bronfenbrenner, Kessel, Kessen \& White, 1986; Elder, 1974; Lerner \& Kauffman, 1985).

In order to understand individual development better, the context in which it occurs needs to be studied. For this reason, the contextualist approach focuses on the study of development and individual behavior within the corresponding cultural context. Following the same line of reasoning, Valsiner $(1987 ; 1989)$ argues for a "culture-inclusive developmental psychology", and Super and Harkness (1986) focus on the "developmental niche". A contextualist approach to development takes into account the mutual relationship between culture and individual behavior. The researcher may thereby become more sensitive to implicit Western ethnocentrism and the cultural embedment of psychological theorizing as has been pointed out by social constructionists (cf., Gergen, 1985).

However, certain problems arise from a purely "culture-inclusive" position. Starting from a culture-specific ("emic") approach, one may argue that theoretical concepts and methodologies employed to gain empirical data should be restricted to the given cultural context and not be considered valid across cultures. This requires the use of ideographic methods, aimed at "understanding" behavior. In contrast, the cross-cultural nomothetic ("etic") approach assumes the universal validity of Western concepts and methodologies and aims to "explain" behavior. Accordingly, the "emic" approach favors a relativistic and the "etic" approach a universalistic position (e.g., Segall, 1993; Shweder, 1990; Van de Vijver \& Hutschemaekers, 1990).

We believe that both positions have their advantages and disadvantages: Though culture influences individual behavior early in development, we have to acknowledge certain universal, e.g., biological, boundaries and processes (Kornadt, 1993; Trommsdorff, 1993b). Accordingly, cultural variables (entering 
into more or less proximate contexts such as family, society, and religion) and biological factors affect individual behavior as the person interacts with his/her environment. Therefore, both the multilevel bases of individual behavior and their interrelations should be emphasized.

Cross-cultural studies are necessary in order to gain more systematic knowledge about the quality of relations between individual and culture. However, such cross-cultural studies cannot be carried out simply by focusing on a single cultural variable serving as the "independent" or antecedent variable. Instead, the cultural context should be taken into account. Cultures constitute multidimensional systems including historical, societal, political, and religious aspects, thereby comprising various contexts of meaning. This is in accordance with Geertz (1973) who defines culture as a system of meanings: "It is a historically created system of meanings, in terms of which we give form, order, point and direction to our lives" (p. 32). Applying this perspective, individual behavior (and social interaction) have a certain "meaning" for the person and for his or her environment, which varies according to the cultural context. People react to this behavior according to its meaning, thus reacting to and recreating complex social representations (Moscovici, 1982; 1984) of which one is not necessarily (explicitly) aware.

In accordance with this view, cross-cultural comparisons of certain behaviors must take into account the specific cultural context by which a certain meaning is connected to the behavior in question (cf., Whiting, 1976). On this basis, an emic perspective can enter into an etic procedure, yielding more valid results using cross-cultural methods and a more appropriate interpretation of cross-cultural data. From this point of view, research on development should make use of not only cross-cultural, but also historical-comparative studies (e.g., Smith, 1978) at least when systematic processes of social change are to be studied.

\section{Social Change and Adolescent Development in Different Cultural Contexts}

\subsection{Social Change, Cultural Contexts, and Adolescent Development}

Here, social change is considered to include different forms of societal processes from partial to complete transformations of social, economic and political systems. These may affect the cultural context of the individual and, thus, change aspects of his or her material ("objective") resources, belief system and behavior. On the other hand, individual behavior (e.g., political participation; consumption pattern) can induce social, economic and cultural change. Therefore, social change and individual behavior are interrelated by the given cultural context which gives meaning to both the kind of social change and individual behavior. 
When talking about social change, we thus take into account the multilevel organization of social behavior and the interdependent relations between the macro, meso and micro level of the social system. Accordingly, social change is related to changes in individual behavior, and both are related to changes in the cultural context. Social change like modernization, therefore, can have different meanings according to the respective cultural belief system and the way the individual interprets related changes in the political and social systems, e.g., in Japan traditional values may promote economic development and thus can coexist beside modern behavior (Bellah, 1971; Bendix, 1966/67; Trommsdorff, 1983; Trommsdorff, Suzuki \& Sasaki, 1987).

Social change implies changes in the socialization conditions of children and adolescents. For instance, economic changes affecting occupational opportunities also affect family life (e.g., time budget for interactions), parental goals, childrearing behavior, and the quality of parent-child relations. Social changes may also be related to changes in the educational system and in the quality of informal social relations with peers. This again may affect the development of children and adolescents. Adolescent development is especially sensitive to social change since adolescents assimilate social environments, and they also accommodate to them. Adolescents are in a period of transition into adulthood which may also mean transition into social change.

The effects of socioeconomic change have been demonstrated in the famous studies by Elder (1974). Age and gender were among the developmental factors which moderated the effects of the Great Depression. Whether social changes create opportunities or obstacles depends partly on adolescents' previous development and related belief system. Consequently, social changes are interpreted and acted upon differently. Therefore, according to cultural and individual variations in adolescents' relation to the social environment, different reactions to and stimulation of social change should be expected.

\subsection{Parent-Child Relationship in Cultural Context}

Parent-child relations differ according to the child's age and the culturally defined developmental tasks for the child. The study of parent-child relations during adolescence is especially informative since this relation is organized around the culture-specific transition of adolescents into the adult role and related developmental tasks. The quality and the culture-specific meaning of such tasks may differ considerably, and they may be related to the quality of parent-child relationships. Usually, in Western cultures, achieving identity, autonomy, and independence are considered the most important developmental tasks of adolescence.

Parent-child relationships are organized according to the sociocultural values which serve as one of the main bases for the socialization and development of adolescents. On the one hand, the study of parent-child relations allows us to gain 
insight into certain aspects of the family -- still the main agent of socialization in modern and traditional societies. On the other hand, it allows us to analyze aspects of the society and cultural context because in parent-child relations, social roles and cultural values are transmitted as part of the socialization processes. Thus, in parent-child relations, individual and societal needs meet.

The study of parent-child relations during adolescence allows us to focus on the interrelations between individual development and societal and cultural conditions. Therefore, one may even ask which developmental conditions, as represented in the relationship between adolescents and their parents, are indicators of social change or stability. The quality of parent-child relations also affects the way adolescents deal with social change and whether they prefer challenging opportunities or risks. When the relation between adolescents and their parents is close, traditional patterns of behavior may be preserved. Alternatively, a loose or conflictive relation between the two generations may promote social change. In this way, the quality of parent-child relations in adolescence may indirectly affect social change; such as when the detachment of adolescents from their parents' values gives rise to more than just an age-related value change. On the other hand, social change (e.g., economic hardship) may affect the quality of parentchild relations, inducing more independent or interdependent relations.

Besides the fact that the quality of intergenerational relations both influences and is affected by the type and speed of social change, processes of social change and also of intergenerational relations always take place in specific cultural contexts. Such cultural contexts structure the way social change proceeds; they affect not only parent-child relations, but also the way that these relations change and affect social systems. Therefore, the assumed relation between social change and parent-child relations must be studied with respect to the cultural context.

A large number of cross-cultural studies on parent-child relations focuses on the style of parental socialization, such as acceptance and rejection or different kinds of conformity demands (Munroe \& Munroe, 1975; Rohner, 1975). Most research on child-rearing, however, produces inconsistent results when the meaning of parental behavior for both parents and children is neglected. Recent studies of parent-child relations, therefore, have investigated subjective theories of the parent-child relationship; these studies focus on parents' and children's subjective beliefs regarding child development or the roles of parents and adolescent children (Goodnow et al., 1986; Kornadt \& Trommsdorff, 1990; Sigel, 1985). Such subjective theories have been viewed as influential culture-specific aspects of the "developmental niche" (Super \& Harkness, 1986). In the past, research on the child's perspective has been neglected, mostly out of practicality because infants or preschool children were the subjects. The interaction quality of parent-child relations has also been neglected. For these reasons, this study investigates the quality of interaction between the adolescent and his/her parents by focusing on the perspective of the adolescent. The purpose is to gain insight 
into the ways adolescents structure person-environment relations in different cultural contexts.

\subsection{Hypotheses on Cultural Differences in Adolescents' Relations to Parents}

Individualistic vs. collectivistic cultures. The differentiation between "collectivistic" and "individualistic" cultures was introduced into cross-cultural studies by Hofstede (1980) and has proven very fruitful. It has stimulated not only considerable empirical research, but also criticism regarding the explanatory value of this variable when this construct is reduced to only one dimension (cf., Schwartz, 1990). Individualistic as compared to collectivistic cultures can be described as placing higher value on individual goals than social ones and higher value on independence than on conformity. In individualistic cultures, competition is valued more than cooperation, and ingroup-outgroup differentiation is valued less (e.g., Triandis, 1985; 1989; 1990).

These different value orientations are assumed to influence socialization experiences and the development of adolescents in such a way that adolescents from collectivistic cultures become more oriented to social values than to individualistic ones. Their search for identity is presumably more focused on aligning themselves with their group than on independence. It could well be assumed that individual identity is a typical Western construct as the recent discussions on self and identity by Smith (1978), Marsella, DeVos and Hsu (1985), and Markus and Kitayama (1991) have shown. Accordingly, culture-specific differentiations for self development and identity formation are necessary (Triandis, 1989). In collectivistic cultures, a rather "interdependent" self develops in contrast to the more "independent" self which develops in individualistic cultures (cf., Markus \& Kitayama, 1991). While in collectivistic cultures, the self becomes more and more embedded in social relationships; in individualistic cultures, self development is focused on achieving autonomy and independence. Developmental tasks during adolescence should differ accordingly. Adolescents in collectivistic as compared to individualistic cultures presumably experience more cooperation and emotional support and, at the same time, stronger social demands for integration, conformity and obedience. This may induce a preference for conformity and obedience while simultaneously establishing a positive and emotionally warm and harmonious social relationship in which the individual person has his or her distinct place and feels secure. In accordance with these differentiations, the developmental tasks of adolescents living in these two cultural contexts should differ, e.g., more autonomy and less conformity should be demanded in individualistic cultures than in collectivistic ones. Adolescents living in different cultural contexts may participate in different socialization experiences as reflected in parental goals and behavior and parent-child relations, especially in conflicting interactions. 
One main developmental task of adolescence is to build up satisfying relations with peers and to achieve social competence in relating to peers. This developmental task may again be understood differently in different cultural contexts. It can be assumed that adolescents in collectivistic as compared to individualistic cultures differ with respect to relating to peers. In a collectivistic group-oriented cultural context, this task may mean a further step towards achieving interdependence. Since it is so important for group-oriented societies to establish positive social relations, at least with members of the in-group, it can be assumed that parents will try very hard to prevent conflicts between their child and peers. Furthermore, it can be expected that adolescents from collectivistic as compared to individualistic cultures experience a stronger normative and controlling behavior of their parents in peer as compared to non-peer situations.

Individualistic and modern us. collectivistic and traditional cultures. In considering cultural differences, two important questions arise: (1) are parent-child relations in modern cultures the same as in individualistic ones?, and (2) are parent-child relations in traditional cultures the same as in collectivistic ones?

For highly modernized societies, it is implicitly or explicitly assumed that individualism is not only the typical, but also the functionally necessary value orientation. Individualism has been conceived of as a major source of economic achievement and modernization (cf., Max Weber's study on the Protestant Ethic, 1920). However, the assumption that individualism is a functional prerequisite for or a consequence of achievement, economic success, and modernization, cannot be held in light of cross-cultural research including Japan (Bellah, 1971; Bendix, 1966/1967). The rapid modernization of Japan and Japan's enormous success as the leading economic power in the world cannot be explained by referring to individualistic values.

On the contrary, Japanese society has preserved a highly group-oriented structure which affects all areas of daily life (Kornadt \& Trommsdorff, 1993). The socialization of Japanese children and adolescents is characterized by giving priority to group goals; the individual person learns first to be a part of the social group and to contribute to the social harmony in this group. Here, collectivistic values are of high importance. Thus, when we take into account a highly modernized society such as Japan where the collectivistic values of group-orientation and mutual obligations are highly valued, the global differentiation between individualistic vs. collectivistic cultures does not necessarily coincide with modernity vs traditionality (Hayashi \& Suzuki, 1990; Trommssdorff, 1983, 1989).

Several studies have demonstrated strong differences between Japanese and American or German samples with respect to child-rearing in such areas as mothers' goals and practices and mother-child relations (Azuma, 1986; Stevenson et al., 1986; Kornadt \& Trommsdorff, 1990; Trommsdorff, 1984, 1993a; Trommsdorff \& Friedlmeier, 1993). One main finding is that Japanese motherchild relations are characterized by more harmony and a closer emotional bond 
("amae") than Western mother-child relations. From a developmental point of view, we cannot assume necessarily that this relation remains stable over the life span or characterizes parent-adolescent relations. New developmental tasks have to be fulfilled by adolescents, especially in modern societies which are undergoing rapid economic changes.

These results regarding differences between parent-child relations in Japan and Germany challenge the view that adolescent development in highly modernized cultures must follow the same pattern of person-enviromnent relations focused on the independence of the individual. Therefore, it must be questioned whether the developmental task of adolescents to achieve "identity" has the same meaning across cultures. For adolescents who have grown up in a cultural context which places a high value on close family relationships, the developmental task of achieving individual identity should be less important than achieving a socially-embedded identity. Accordingly, parent-child interactions in this context focus more on conformity and compliance. Culturally different paths of individual development may exist depending on the given context.

One may assume that Japanese adolescents' relationships with their parents reflect both a "collectivistic" or group orientation and certain individualistic values of modern societies. Indonesian tradition strictly adheres to the values of group harmony and gives priority to group goals over individual interests. Social groups are structured according to strict rules, mainly with respect to seniority (cf., Geertz, 1961; Magnis-Suseno, 1989; Pidada, 1993). In the traditional Batak and Balinese cultures, children and adolescents grow up in a hierarchically organized, closely knit system of specific social obligations according to the moral code of the "adat". The details of the "adat" rules may differ from one extended family and village to another. However, the "adat" rules are basically similar, e.g., respect towards one's elders, acceptance of asymmetric relations in the family, and serving the forefathers in highly specified ways. Here, similiarities with traditional Japanese social values can be seen on a global level. Therefore, despite considerable differences in the degree and kind of modernization in Japan and Indonesia, adolescents from these societies should be similar with respect to certain collectivistic values of group orientation and establishment of group harmony.

Accordingly, Japanese and Indonesians are compared to each other and also to West European adolescents. It is hypothesized that parent-adolescent relationships reflect patterns of group orientation most distinctly in Indonesian (traditional), moderately in Japanese (modern), and least in Western European (modern) samples.

Different degrees of modernization can also be observed within a society. For instance, in Indonesia, Balinese and Batak adolescents presumably experience somewhat different contexts of transition to modernity, especially with respect to economic improvement and social mobility. Batak adolescents from Sumatra do not encounter much modernization unless they move to the big cities on Java. 
Balinese adolescents, on the other hand, are mostly confronted with specific aspects of modernization which are less transmitted by their own people than by foreigners. Balinese can observe certain select aspects of modernization in tourist centers without engaging in mobility and without having much opportunity to observe the processes of transition to modernity and its related sociocultural conflicts and problems. Modernization on Bali is concentrated in the capital and the tourist locations and mostly represents the taste and consumer behavior of tourists from Western industrialized societies. Therefore, it seems useful to include an intra-cultural comparison of Indonesian adolescents in order to take into account different degrees of modernization in a specific cultural context.

A further differentiation of cultural contexts is related to religious values. It can be assumed that cultural values and the religious system are interrelated, and that both affect the cultural context and the socialization conditions of adolescents. For our present purposes, religious values are of particular interest because they differently structure the person-environment relation (e.g., individualism and self-reliance vs. social and religious rules of behavior). It is assumed that values of self-environment relations differ in monotheistic (e.g., Christian) vs. nonmonotheistic cultures (e.g., Hindu or Buddhist), e.g., identity and self-concept differ in such religious systems (Johnson, 1985). Developmental tasks and the socialization experience in monotheistic cultures focus on the development of the autonomous individual self. In contrast, the Hindu-Buddhist cultures view the self as embedded in the social group. Taking into account such cultural differences in self development is in line with critical remarks by Waterman (1981), Spence (1987), and Markus and Kitayama (1991) on the ethnocentric individualistic conceptualization of the self.

In our study on cultural differences in parent-adolescent relations, samples from Christian and Buddhist-Hindu societies will therefore also be included. The Indonesian society follows specific Malaysian values as described by Geertz (1961). However, in Indonesia, many ethnic cultural groups are living together. Some such as the Batak and Balinese differ from each other on account of religious values.

Though Indonesia is mostly Islamic (about $90 \%$ ), some non-Islamic groups exist. Batak adolescents (originally from Sumatra) usually grow up in Christian communities while Balinese have preserved their Hinduistic culture. The Christian religion does not constitute the indigenous cultural value system of the Batak; it has been imposed on them by the Christian missionaries since the beginning of the 20th century and presumably is transmitted further through formal education and socialization in school and church.

This focus on different aspects of the cultural context as the "developmental niche" underlines how important it is to look at possible intra-cultural differences and to break up complex sociocultural groups into sub-groups which may differ according to theoretically interesting variables. A comparison between Asian (e.g., Japanese and Indonesian) and European (e.g., German and Scottish) sam- 
ples may only allow for global comparisons between collectivistic and individualistic cultures. Such a grouping does not seem appropriate when taking into account possible relations between modernization and parent-child relations. For this latter question, a comparison between each of the cultures is more appropriate.

\section{Method}

\subsection{Samples}

The present study does not compare cultures, but rather different samples of adolescents who are growing up in different cultural contexts. According to the previous theoretical outline, in each cultural context samples from different societies (and for Indonesia, different ethnic groups) were included -- in Western Europe, Germany and Scotland, and in East Asia, Japan and Indonesia (Bali, Batak). These societies represent certain cultural variables which are of interest to our present study. Therefore, the above-named societies were grouped in the following way:

1. modern: Germany, Scotland, and Japan;

traditional: Bali and Batak (two Indonesian subcultures of Sumatra and Java);

2. individualistic: Germany and Scotland; collectivistic: Japan, Bali and Batak;

3. Christian: Germany, Scotland and Batak; Buddhist-Hindu: Japan and Bali.

In each of these cultures, adolescents between 16 and 18 years of age participated. They were chosen from high schools (two cities in each culture). The sample size varied (Bali $N=14$; Batak $N=14$; Japan $N=9$; Germany $N=20$; Scotland $N=20$ ). All subjects participated voluntarily. Adolescents were approached via school teachers.

\subsection{Instruments}

All subjects were interviewed on the basis of a semi-structured test depicting seven different everyday conflict situations between an adolescent and his or her parents (Kornadt, 1989; Kornadt et al., 1991). Four of these situations focused on a conflict between the adolescent and the parents and the remaining three situations focused on a conflict between the adolescent and a peer.

These two types of situations were selected because social conflicts in everyday situations sometimes involve only dyadic interaction between an adolescent 
and his/her parents and sometimes include a peer. An example of the first type of situation: The adolescent comes home late and the mother has been waiting up for him/her. An example of the second type of situation: The adolescent reports to his/her parents that a peer has refused to help him/her do his/her homework.

For each of the seven situations, the adolescents were asked to describe how the father/mother reacted, why he/she reacted like this, how he/she felt in this situation, how he/she interpreted the adolescent's intentions, how the adolescent him/herself behaved and felt, and how the situation ended. Thereby, the subjective meaning of the interaction should become clear for each situation.

These tasks and interviews were pilot-tested and modified to ensure the crosscultural equivalence of the methods. Thus, it was ascertained that the stimulus material had an equivalent meaning in all cultures. All interviewers were trained and the same procedure for collecting data was carried out in each culture. Translation and backtranslation of the stimulus material and of the interviews was done to check for culture-specifities of meaning.

The adolescents' answers were coded according to several theoretically relevant categories, e.g., the kind of parental behavior, goals, attributions and emotions; adolescents' behavior and emotions, and the quality of the parent-child relationship. Each of the subjects' answers was coded and the frequencies of the answers for each of the categories were calculated. For each of the categories (e.g., parental goals, etc.), the frequencies (in percent) were averaged for each situation (in each of the two types of situations). For each of the categories (and each of the subjects), relative frequencies were used for further statistical analyses (comparisons of mean values). In the following section, average relative frequencies (in percentages) for each sample (or each cultural group) are reported.

\section{Results}

Parents' goals and intentions. When answering questions about stories describing a conflict between parent and adolescent (Situations 1-4), both parents' goals for conformity and child-oriented goals, were mentioned more often by adolescents from traditional (Bali, Batak) or collectivistic (Bali, Batak, Japan) than by adolescents from modern (Germany, Scotland, Japan) or individualistic (Germany, Scotland) contexts $(t=6.25, t=7.06, t=3.60$, and $t=$ 3.50 , respectively; $p<.001$ ) (see Table la and $1 \mathrm{~b}$ and Figure 1 ).

Analyses of variance also showed significant differences for both types of goals $(F=25.53, p<.001$; and $F=3.49, p<.05$, respectively) (see Table lc).

Furthermore, comparisons between Japanese adolescents and adolescents from other cultural contexts showed significant differences only for conformity goals. Japanese adolescents mentioned parental goals of conformity less often 
Table 1a: Interaction Between Adolescents and Parents in Conflict Situations: Means and Standard Deviations for Each Culture

\begin{tabular}{|c|c|c|c|c|c|c|c|c|c|c|}
\hline & \multicolumn{2}{|c|}{ Bali } & \multicolumn{2}{|c|}{ Batak } & \multicolumn{2}{|c|}{ Japan } & \multicolumn{2}{|c|}{ Germany } & \multicolumn{2}{|c|}{ Scotland } \\
\hline & $M$ & $S D$ & $M$ & $S D$ & $M$ & $S D$ & $M$ & $S D$ & $M$ & $S D$ \\
\hline \multicolumn{11}{|c|}{ Parents' Goals and Intentions } \\
\hline Conformity & .66 & .20 & .74 & .26 & .54 & .24 & .43 & .28 & .05 & .10 \\
\hline Child focused goals & .69 & .28 & .66 & .29 & .54 & .21 & .43 & .27 & .43 & .28 \\
\hline \multicolumn{11}{|l|}{ Parents' Behavior } \\
\hline Child orientation & .88 & .26 & .64 & .25 & .76 & .23 & .68 & .28 & .65 & .25 \\
\hline Awareness of child's noeds & .36 & .24 & .26 & .17 & .46 & .14 & .45 & .13 & .45 & .15 \\
\hline Flexibility & .73 & .28 & 63 & .35 & .63 & .16 & .58 & .29 & .53 & .32 \\
\hline Helping & .19 & .21 & .16 & .18 & .31 & .21 & .11 & .17 & .03 & .08 \\
\hline Explaining & .39 & .23 & .33 & .23 & .23 & .20 & 19 & .18 & .11 & .13 \\
\hline Praising & .35 & .22 & .29 & .25 & .11 & .13 & 19 & .21 & .05 & .10 \\
\hline Control & .33 & .16 & .14 & .16 & .30 & .23 & .06 & .11 &, 00 & .00 \\
\hline Conformity demands & .43 & .24 & .49 & .20 & .45 & .32 & .20 & .17 & .38 & .34 \\
\hline Obedience demands & .28 & .27 & .21 & .22 & .20 & .25 & .10 & .13 & .13 & .26 \\
\hline \multicolumn{11}{|l|}{ Adolescents' Behavior } \\
\hline Giving in & .33 & .28 & .26 & .24 & .19 & .21 & .09 & .19 & .15 & .17 \\
\hline Cooperation & .73 & .29 & .73 & .27 & .54 & .29 & .59 & .30 & .55 & .30 \\
\hline Understanding & .21 & .18 & .34 & .23 & .18 & 18 & .18 & .22 & .15 & .19 \\
\hline Feeling secure & .20 & .20 & .22 & .23 & .00 & .00 & .03 & .11 & .03 & .08 \\
\hline \multicolumn{11}{|l|}{ Parent-Child Relation } \\
\hline Harmony & .61 & .25 & .64 & .27 & .60 & .27 & .46 & .23 & .43 & .30 \\
\hline Mutual understanding & .57 & .29 & .48 & .31 & .49 & .26 & .33 & .23 & .36 & .26 \\
\hline
\end{tabular}

Note. Relative frequencies of reported events. 
Table 1b: Interaction Between Adolescents and Parents in Conflict Situations: Comparisons Between Groups of Cultures (Mean Values)

\begin{tabular}{|c|c|c|c|c|c|c|c|c|c|}
\hline & Collect. & Indiv. & Trad. & Modem & $\begin{array}{l}\text { Hind./ } \\
\text { buddh. }\end{array}$ & Christ. & $\begin{array}{c}t \text {-value } \\
\text { (coll--indiv.) }\end{array}$ & $\begin{array}{c}t \text {-value } \\
\text { (trad,-mod.) }\end{array}$ & $\begin{array}{l}t \text {-value } \\
\text { (religion) }\end{array}$ \\
\hline \multicolumn{10}{|c|}{ Parents' Goals and Intentions } \\
\hline $\begin{array}{l}\text { Conformity } \\
\text { Child focused goals }\end{array}$ & $\begin{array}{l}.66 \\
.64\end{array}$ & $\begin{array}{l}.24 \\
.43\end{array}$ & $\begin{array}{l}.70 \\
.68\end{array}$ & $\begin{array}{l}.29 \\
.45\end{array}$ & $\begin{array}{l}.61 \\
.63\end{array}$ & $\begin{array}{l}.37 \\
.49\end{array}$ & $\begin{array}{l}7.06^{* * * *} \\
3.50^{* * *}\end{array}$ & $\begin{array}{l}6.25^{* * *} \\
3.60^{* * *}\end{array}$ & $\begin{array}{l}3.66^{* *} \\
2.03^{*}\end{array}$ \\
\hline \multicolumn{10}{|l|}{ Parents' Behavior } \\
\hline Child orientation & .76 & .66 & .76 & .68 & .84 & .66 & 1.66 & 1.28 & $2.80^{* *}$ \\
\hline Awareness of child's need & .35 & .45 & .31 & .45 & .40 & .40 & $2.54^{*}$ & $3.13^{* *}$ & $<1.00$ \\
\hline Flexibility & .66 & .55 & .68 & .56 & .69 & .57 & $1.71^{+}$ & 1.58 & 1.63 \\
\hline Helping & .21 & .07 & .18 & .11 & .24 & .09 & $3.49^{* * *}$ & 1.44 & $2.92^{* *}$ \\
\hline Explaining & .33 & 15 & .36 & .16 & 33 & .20 & $3.98^{* * *}$ & $4.29^{* * *}$ & $2.51^{*}$ \\
\hline Praising & .27 & .12 & .32 & .12 & .25 & .16 & $3.18^{* *}$ & $4.41^{* * * *}$ & 1.65 \\
\hline Control & .25 & .03 & .24 & .08 & .32 & .06 & $6.29^{* * *}$ & $3.80^{* * *}$ & $6.02^{* * *}$ \\
\hline Conformity demands & .46 & .29 & .46 & .32 & .44 & .34 & $2.91_{* *}^{* *}$ & $2.31^{*}$ & 1.49 \\
\hline Obedience demands & .23 & .11 & .24 & .13 & .25 & .14 & $2.39^{*}$ & $2.16^{*}$ & $2.00^{*}$ \\
\hline \multicolumn{10}{|l|}{ Adolescents' Behavior } \\
\hline Giving in & .27 & .12 & .30 & .13 & .28 & .16 & $3.06^{* *}$ & $2.99^{* *}$ & $2.19^{*}$ \\
\hline Cooperation & .68 & .57 & .73 & .56 & .65 & .61 & $1.74^{+}$ & $2.44^{*}$ & $<1.00$ \\
\hline Understanding & .25 & .16 & .27 & .16 & .20 & .21 & $1.88^{+}$ & $2.28^{*}$ & $<1.00$ \\
\hline Feeling secure & .16 & .03 & .21 & .02 & .12 & .08 & $3.65^{* * *}$ & $4.55^{* * *}$ & 1.12 \\
\hline \multicolumn{10}{|l|}{ Parent-Child Relation } \\
\hline Harmony & .62 & .44 & .62 & .47 & $.6 \mathrm{I}$ & .49 & $2.90^{* *}$ & $2.35^{*}$ & 1.65 \\
\hline Mutual understanding & .51 & .34 & .52 & .37 & .54 & .38 & $2.80^{* *}$ & $2.34^{*}$ & $2.36^{*}$ \\
\hline
\end{tabular}

Nore. Relative frequencies of reported events.

$$
+=p<.10 ;{ }^{*}=p<.05 ;{ }^{* *}=p<.01 ;{ }^{* * *}=p<.001 \text {. }
$$


Table 1c: Interaction Between Adolescents and Parents in Conflict Situations: Analyses of Variance

$F$-value

significant differences

(Scheffe-Test)

\section{Parents' Goals and Intentions}

Conformity

Child Focused Goals

$$
25.53^{*}
$$

$3.49^{*}$

$\mathrm{Bk}>\mathrm{G} ; \mathrm{Bk}>\mathrm{S} ; \mathrm{Bi}>\mathrm{S} ; \mathrm{J}>\mathrm{S} ; \mathrm{G}>\mathrm{S}$

$\underline{\text { Parents' Behavior }}$

Child Orientation

\section{$2.22^{+}$}

Awareness of childs needs

$3.64^{* *}$

Flexibility

Helping

Explaining

Praising

Control

Conformity Demands

Obedience Demands

$$
1.02
$$

$5.14^{* *}$

$5.47^{* * *}$

$6.50^{* * *}$

$16.37^{* * *}$

$3.40^{*}$

1.65

$\mathrm{G}>\mathrm{Bk} ; \mathrm{S}>\mathrm{Bk}$

$J>S$

$\mathrm{Bi}>\mathrm{S} ; \mathrm{Bk}>\mathrm{S}$

$\mathrm{Bi}>\mathrm{S} ; \mathrm{Bk}>\mathrm{S}$

$\mathrm{Bi}>\mathrm{Bk} ; \mathrm{Bi}>\mathrm{G} ; \mathrm{Bi}>\mathrm{S} ; \mathrm{J}>\mathrm{G} ; \mathrm{J}>\mathrm{S}$

$\mathrm{Bk}>\mathrm{G}$

Adolescents' Behavior

Giving in
Cooperation
Understanding Parents
Feeling Secure

$3.25^{*}$

1.5

$2.09^{+}$

$7.56^{* * *}$

$\mathrm{Bi}>\mathrm{G}$

$\mathrm{Bk}>\mathrm{S} ; \mathrm{Bk}>\mathrm{G} ; \mathrm{Bk}>\mathrm{J} ; \mathrm{Bi}>\mathrm{S} ; \mathrm{Bi}>\mathrm{D} ; \mathrm{Bi}>\mathrm{J}$

\section{Parent-Child Relation}

Harmony

$$
2.11^{+}
$$

Mutual Understanding

than adolescents from traditional/collectivistic cultures (Balinese, Batak) and more often than adolescents from individualistic/modern cultures (Germany, Scotland) $(t=1.79, p<.10$ and $t=2.97, p<.01$, respectively) (see Table 2).

Parents' behavior. With respect to conflicts between adolescents and their parents (situations 1-4), analyses indicate that significant differences between the five cultures occured, $(F=2.22, p<10)$ (cf., Table lc). East Asian as compared to European adolescents tended to report more child orientation of parents and less parental awareness of childs' needs $(F=3.64, p<.01$ ) (see Tables 1a and 1c). The latter result was due to lower values for traditional as compared to 


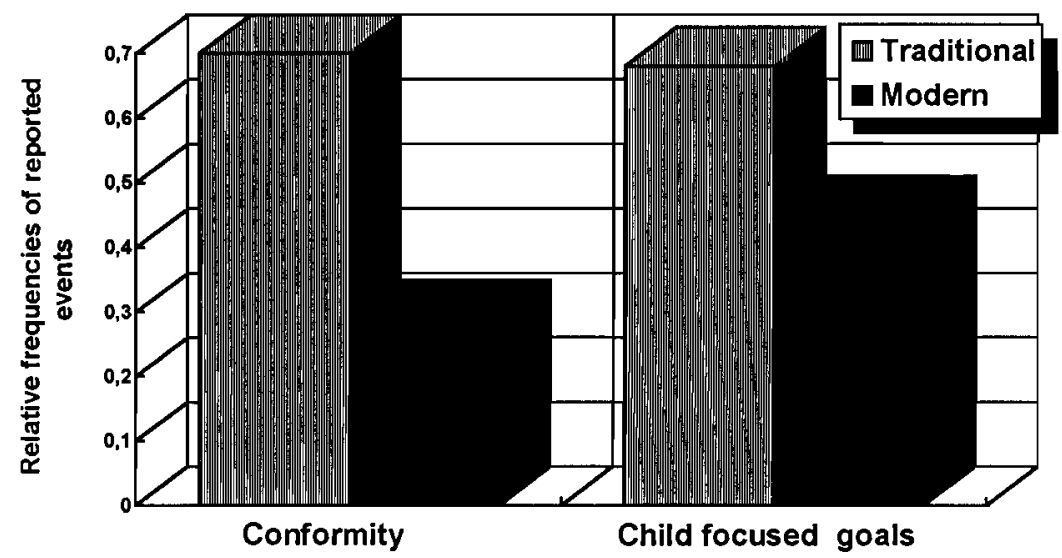

Figure 1: Parents' Goals and Intentions in Modern and Traditional Societies

modern cultural groups and collectivistic as compared to individualistic cultural groups $(t=3.13, p<.01$, and $t=2.54, p<.05$ ) respectively (see Tables la and 1b). Furthermore, East Asian as compared to European adolescents reported both more supportive (explaining, praising) and more controlling (control, demanding conformity and obedience) parental behavior (see means, $t$ - and $F$-values for each variable on Tables $1 \mathrm{a}, 1 \mathrm{~b}$, and $1 \mathrm{c}$ ). Comparisons between each society by analyses of variance and between the different cultural groups by $t$-tests demonstrated that each variable has to be studied separately. Parental control was different for adolescents from the five societies $(F=16.37, p<.001)$ (see Tables la, $1 \mathrm{~b}$, and $1 \mathrm{c})$.

Furthermore, Japanese adolescents were sometimes quite similiar to adolescents from other collectivistic groups as well as sometimes similiar to adolescents from other modern groups. For instance, with respect to "helping" and "controlling" Japanese adolescents were more similiar to Balinese and Batak and more different from German and Scottish adolescents $(t=4.26, p<.001 ; t=$ $3.43, p<.01$, respectively) (see Table 2). For "praising" the differences reversed: Japanese were more similiar to German and Scottish and more different from Balinese and Batak adolescents $(t=2.63, p<.05)$ (see Table 2$)$.

When the adolescent was involved in a conflict with a peer (situations 5-7), East Asian adolescents, especially Indonesian adolescents, reported significantly more parental control than did Japanese and European adolescents. Japanese adolescents reported more control than German and Scottish adolescents $(t=3.02, p$ $<.01)$, and they reported less control than Bali and Batak adolescents $(t=2.74, p$ $<.01$ ) (see Tables 3a, 3b, and 3c). $T$-tests for dependent samples showed that except for adolescents from individualistic groups, parental control was more frequent for situations involving a peer rather than a dyadic parent-child situation (see Table 3b). 
Table 2: Japanese vs. Collectivistic/Traditional and Individualistic/Modern Adolescents

\begin{tabular}{|c|c|c|c|c|c|c|c|c|}
\hline & \multicolumn{2}{|c|}{ Japan } & \multicolumn{2}{|c|}{$\begin{array}{c}\text { collectivistic/ } \\
\text { traditional } \\
\text { Bali/ } \\
\text { Batak }\end{array}$} & \multicolumn{2}{|c|}{$\begin{array}{c}\text { individualistic/ } \\
\text { modern } \\
\text { Germany/ } \\
\text { Scotland }\end{array}$} & \multirow{2}{*}{$\begin{array}{c}\mathrm{t}_{1} \\
\text { collectivistic } \\
\text { traditional }\end{array}$} & \multirow{2}{*}{$\begin{array}{c}\mathrm{t}_{2} \\
\text { individualistic } \\
\text { modern }\end{array}$} \\
\hline & $M$ & $S D$ & $M$ & $S D$ & $M$ & $S D$ & & \\
\hline \multicolumn{9}{|l|}{ Parents' Goals and Intentions } \\
\hline Conformity & .54 & .24 & .70 & .23 & .24 & .28 & $1.79^{+}$ & $2.97^{* *}$ \\
\hline Child focused goals & .54 & .21 & .68 & .28 & .43 & .27 & 1.38 & 1.14 \\
\hline \multicolumn{9}{|l|}{ Parents' Behavior } \\
\hline Child orientation & .76 & .23 & .76 & .28 & .66 & .26 & $<1.00$ & 1.08 \\
\hline Awareness of child's needs & .46 & .14 & .31 & .21 & .45 & .14 & $1.92^{+}$ & $<1.00$ \\
\hline Flexibility & .63 & .16 & .68 & .31 & .55 & .31 & $<1.00$ & 1.15 \\
\hline Helping & .31 & .21 & .18 & .19 & .07 & .14 & $1.77^{+}$ & $4.26^{* * *}$ \\
\hline Explaining & .23 & .20 & .36 & .23 & .15 & .16 & 1.50 & 1.33 \\
\hline Praising & .11 & .13 & .32 & .23 & .12 & .18 & $2.63^{*}$ & $<1.00$ \\
\hline Control & .30 & 23 & .24 & .19 & .03 & .08 & $<1.00$ & $3.43^{* *}$ \\
\hline Conformity demands & .45 & .32 & .46 & .22 & .29 & .28 & $<1.00$ & 1.57 \\
\hline Obedience demands & .20 & .25 & .24 & .25 & .11 & .20 & $<1.00$ & 1.17 \\
\hline \multicolumn{9}{|l|}{ Adolescents' Behavior } \\
\hline Giving in & .19 & .21 & .30 & .26 & .12 & .18 & 1.14 & 1.03 \\
\hline Cooperation & .54 & .29 & .73 & .28 & .57 & .29 & $1.75^{+}$ & $<1.00$ \\
\hline Understanding parents & .18 & .18 & .27 & .21 & .16 & .20 & 1.24 & $<1.00$ \\
\hline Feeling secure & .00 & .00 & .21 & .21 & .03 & .09 & $5.27^{* * *}$ & 1.67 \\
\hline \multicolumn{9}{|l|}{ Parent-Child Relation } \\
\hline Harmony & .60 & .27 & .62 & .26 & .44 & .27 & $<1.00$ & 1.62 \\
\hline Mutual understanding & .49 & .26 & .52 & .30 & .34 & .24 & $<1.00$ & 1.63 \\
\hline
\end{tabular}

Note. Relative frequencies of reported events.

$$
+p^{<.10} ;^{*} p^{<.05 ;}{ }^{* *} p<.01 ;{ }^{* * *} p<.001 \text {. }
$$


Table 3a: Controlling Behavior of Parents in Conflict Situations Involving Parent-Child vs. Peer Interactions: Means and Standard Deviations for Each Culture

\begin{tabular}{|c|c|c|c|c|c|c|c|c|c|c|}
\hline & \multicolumn{2}{|c|}{ Bali } & \multicolumn{2}{|c|}{ Batak } & \multicolumn{2}{|c|}{ Japan } & \multicolumn{2}{|c|}{ Germany } & \multicolumn{2}{|c|}{ Scotland } \\
\hline & $M$ & $S D$ & $M$ & $S D$ & $M$ & $S D$ & $M$ & $S D$ & $M$ & $S D$ \\
\hline \multicolumn{11}{|l|}{ Control } \\
\hline Parent-Child & .33 & .16 & .14 & .16 & .30 & .23 & .06 & .11 & .00 & .00 \\
\hline Peer & .68 & .28 & .64 & .29 & .37 & .26 & .23 & .27 & .00 & .00 \\
\hline \multicolumn{11}{|c|}{ Conformity Demands } \\
\hline Parent-Child & .43 & .24 & .49 & .20 & .45 & .32 & .20 & .17 & .38 & .34 \\
\hline Peer & .67 & .22 & .64 & .21 & .63 & .26 & .38 & .31 & .35 & .35 \\
\hline
\end{tabular}

Note. Relative frequencics of reported events. 
Table 3b: Controlling Behavior of Parents in Conflict Situations Involving Parent-Child vs. Peer Interactions: Comparisons Between Groups of Cultures (Mean Values)

\begin{tabular}{|c|c|c|c|c|c|c|c|c|c|c|c|c|}
\hline & Collect. & Indiv. & Trad. & Modern & $\begin{array}{l}\text { Hind./ } \\
\text { buddh. }\end{array}$ & Christ. & $\begin{array}{l}t \text {-value } \\
\text { coll. }\end{array}$ & $\begin{array}{c}t \text {-value } \\
\text { indiv. }\end{array}$ & $\begin{array}{l}t \text {-value } \\
\text { trad. }\end{array}$ & $\begin{array}{l}t \text {-value } \\
\text { modern. }\end{array}$ & $\begin{array}{l}t \text {-value } \\
\text { hind. }\end{array}$ & $\begin{array}{l}t \text {-value } \\
\text { christl. }\end{array}$ \\
\hline \multicolumn{13}{|l|}{ Control } \\
\hline Parent-Child & .46 & .29 & .46 & .32 & .44 & .34 & $3.65^{* * *}$ & $1.45^{* * *}$ & $3.83^{* * *}$ & $1.88^{+}$ & $3.22^{* *}$ & $2.03^{*}$ \\
\hline Peer & .65 & .37 & .65 & .41 & .65 & .43 & & & & & & \\
\hline \multicolumn{13}{|c|}{ Conformity Demands } \\
\hline Parent-Child & .25 & .03 & .24 & .08 & .32 & .06 & $5.43^{* * *}$ & $3.17^{* * *}$ & $6.64^{* * *}$ & $2.70^{* *}$ & $3.00^{* * *}$ & $5.10^{* * *}$ \\
\hline Peer & .59 & .12 & .66 & .16 & .56 & .25 & & & & & & \\
\hline
\end{tabular}

Note. Relative frequencies of reported events.

$t=p<.10 ;{ }^{*}<<.05 ;{ }^{* *} p<.01 ;{ }^{* * *} p<.001$. 
Table 3c: Controlling Behavior of Parents in Conflict Situations Involving Parent-Child vs. Peer Interactions: Japanese vs. Collectivistic/Traditional and Individualistic/Modem Adolescents

\begin{tabular}{|c|c|c|c|c|c|c|c|c|}
\hline & \multicolumn{2}{|c|}{ Japan } & \multicolumn{2}{|c|}{$\begin{array}{c}\text { collectivistic/ } \\
\text { traditional } \\
\text { Bali/ } \\
\text { Batak }\end{array}$} & \multicolumn{2}{|c|}{$\begin{array}{c}\text { individualistic/ } \\
\text { modern } \\
\text { Germany/ } \\
\text { Scotland }\end{array}$} & \multirow{2}{*}{$\begin{array}{c}\mathrm{t}_{1} \\
\text { collectivistic } \\
\text { traditional }\end{array}$} & \multirow{2}{*}{$\begin{array}{c}\mathrm{t}_{2} \\
\text { individualistic } \\
\text { modem }\end{array}$} \\
\hline & $M$ & $S D$ & $M$ & $S D$ & $M$ & $S D$ & & \\
\hline \multicolumn{9}{|l|}{$\underline{\text { Control }}$} \\
\hline Parent-Child & .30 & .23 & .24 & .19 & .03 & .08 & $<1.00$ & $3.43^{* *}$ \\
\hline Peer & .37 & .26 & .66 & .28 & .12 & .22 & $2.74^{* *}$ & $3.02^{* *}$ \\
\hline \multicolumn{9}{|c|}{ Conformity Demands } \\
\hline Parent-Child & .45 & .32 & .46 & .22 & .29 & .28 & $<1.00$ & 1.57 \\
\hline Peer & .63 & .26 & .65 & .21 & .37 & .33 & $<1.00$ & $2.25^{*}$ \\
\hline
\end{tabular}

Note. Relative frequencies of reported events.

$$
{ }^{+} p<.10 ;{ }^{*} p<.05 ;{ }^{* *} p<.01 ;{ }^{* * *} p<.001
$$


3. Adolescents' Behavior. With respect to adolescents' behavior in conflicts with their parents (no peer involved), analyses of variance showed significant differences between the five cultural groups for "giving in" and "feeling secure" ( $F=$ $3.25, p<.05 ; F=7.56 ; p<.001$ ). Adolescents from traditional as compared to modern, cultures and from collectivistic as compared to individualistic cultures showed more "giving in" ( $t=2.99$ and $t=3.06$, respectively; $\mathrm{p}<.01$ ). Following the same pattern, differences between these groups occurred for "cooperation", "understanding", and "feeling secure". Adolescents from each of the traditional cultures (Bali and Batak) reported significantly more security than adolescents from each of the modern cultures (see Tables la and 1c). For example, Japanese adolescents differed significantly from adolescents from the traditional/collectivistic groups $(t=5.27, p<.001)$ (see Table 2 ).

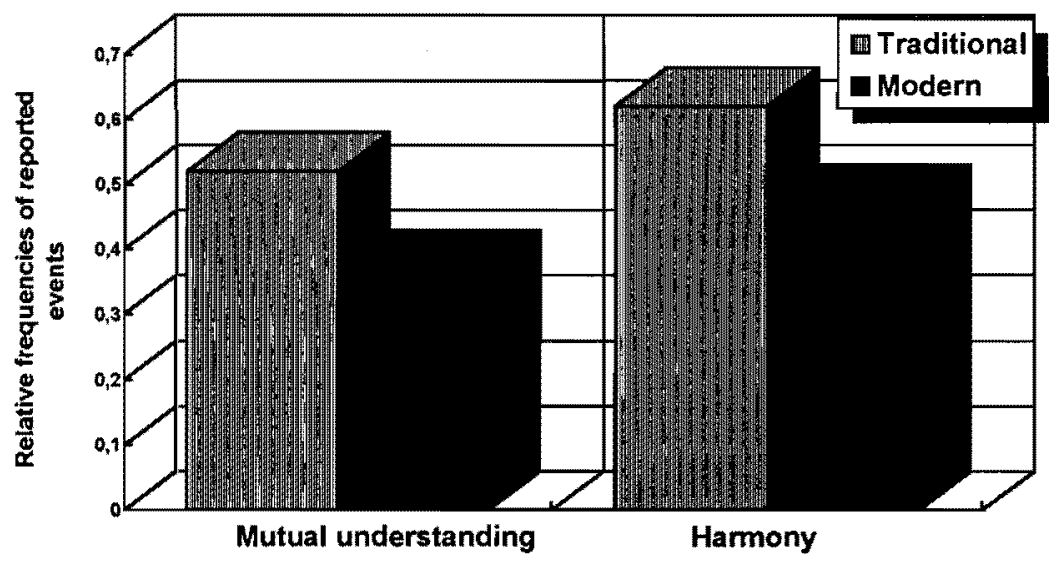

Figure 2: Parent-Child Relations in Modern and Traditional Societies

Parent-child relationship. Adolescents from modern as compared to traditional and also collectivistic as compared to individualistic cultural groups reported more harmony and mutual understanding $(t=2.35 ; 2.90 ; 2.34$; and 2.80 , respectively, $p<.05$ and $<.01$ ) (see Table la). Comparisons between adolescents from the single societies were in the same line $(F=2.11$ and $F=2.17, p<.10)$ (see Tables 1a, 1b, and $1 \mathrm{c}$ and Figure 2).

Correlations between parents' and adolescents' behavior and parent-child relationship. In order to study the theoretically interesting relations between parents' conformity demands and adolescents' behavior, Pearson's correlations were computed, and correlation coefficients for the different cultural groups were com- 
pared using $z$-transformations. While the correlation was not significant when subjects from all cultures were included, positive correlations were found for adolescents from the traditional cultures (Bali and Batak). For the adolescents from modern cultures (Germany, Scotland, and Japan), the correlations between these two variables were negative (see Table 4).

Table 4: Correlations Between Parents' and Adolescents' Behavior and ParentChild Relation in Traditional and Modern Groups

\begin{tabular}{lccc}
\hline & $\begin{array}{c}\text { Parental Con- } \\
\text { formity Demands }\end{array}$ & $\begin{array}{c}\text { Adolescents' } \\
\text { Cooperation }\end{array}$ & $\begin{array}{c}\text { Feeling } \\
\text { secure }\end{array}$ \\
\hline Adolescents' & $.36^{+}$ & & \\
Cooperation & -.15 & & \\
& -.31 & & \\
Feeling & .26 & $.39^{*}$ & \\
secure & -.16 & .22 & \\
& - & - & \\
Harmonious Parent- & $.34^{+}$ & $.71^{* * *}$ & .31 \\
Child Relation & -.08 & $.82^{* * *}$ & .12 \\
& -.24 & $.85^{* *}$ & - \\
\hline
\end{tabular}

\footnotetext{
Note. First row: $r$-values for Bali and Batak $(N=\mathbf{2 8})$; second row: $r$-values for Germany and Scotland $(N=40)$; third row; $r$-values for Japan $(N=9)$; ${ }^{+} p<.10 ;{ }^{*} p<.05 ;{ }^{* *} p_{<.01 ;}^{* * *}{ }_{p<.001}$
}

The difference between the correlation coefficients of these two groups was significant ( $z=2.12$ and $z=1.81$, respectively; $p<.05$ and $p<.10$, respectively).

For the traditional in contrast to the modern groups, parental control was correlated positively with adolescents' feeling secure $r=.26, N=28$, and with a harmonious parent-child relation ( $r=.34, N=28$ ) (see Table 4). The difference between the correlation coefficients of the traditional vs. the modern groups was also significant $(z=1.74, p<.10)$,

To summarize the results, strong cultural differences were found with respect to parental goals and behavior, adolescents' behavior, and the parent-child relationship in the event of a typical everyday conflict between the adolescent and his or her mother or father. Adolescents from traditional as compared to modem and from collectivistic as compared to individualistic cultures reported that their parents' goals were oriented to conformity and to the child's goals and that behavior was characterized by more explaining, praising, control, conformity and obedience demands. These adolescents described themselves as more 
cooperative, understanding, and secure; they perceived their relation with their parents as being more harmonious and based on mutual understanding.

In order to substantiate empirically the preliminary ad-hoc grouping of the cultures, the five cultures were classified into different groups on the basis of computations of the least significant difference. Mean values for these groups were compared using $t$-tests for independent samples. Significant differences occurred for different variables; this showed that for different variables, different classifications of cultures were relevant. Both groupings, modern vs. traditional and individualistic vs. collectivistic, showed different patterns for parental goals. For most of the variables describing parental behovior, the collectivistic vs. individualistic cultural comparisons were most useful. Adolescents' behavior differed most when comparing traditional vs. modern cultures. Parent-child relations showed most differences when comparing collectivistic vs. individualistic cultures. The grouping according to religious values was comparatively less important.

Since certain of these cultural groupings are not independent from each other (Japan is a collectivistic as well as a modern country), Japanese adolescents were analyzed separately in comparison with adolescents from the other two groups (collectivistic/traditional: Balinese and Batak) and individualistic/modern: German and Scottish adolescents). Japanese were more similiar to Balinese and Batak adolescents for some variables (parental control) and, for other variables, more similar to German and Scottish adolescents (low feeling of security).

\section{Discussion}

The responses of adolescents from various cultures give some insight into the way adolescents perceive and evaluate their interactions with their parents in cases of everyday conflicts. However, the methodological limitations of this study should be taken into account. The present data are based on verbal answers from small samples which are not representative of their respective cultures. Therefore, the data do not allow us to generalize about parent-child relations in these cultures. Furthermore, the answers may reflect some social desirability tendencies; these could indicate socio-cultural values. The answers may rather reflect attitudes or the subjective experience and evaluations of "normal" interaction processes between adolescents and their parents in everyday conflicts. The verbal answers may not coincide with actual behavior. Furthermore, it is not certain whether all methods, including the interview procedure, are really culturally equivalent. Several steps were taken to increase the emic and etic validity of the data, e.g., translation and back translation and pilot studies to test the cultural appropriateness of the methods. Finally, on account of an a priori and an empirically based classification of cultures, specific cultures belonged to different groupings at the same time (e.g., Japan is a collectivistic and also a modern cul- 
tural group). Taking these methodological shortcomings into account, what do the data from this comparative study demonstrate?

\subsection{Inter-Cultural Comparisons}

In general, comparisons between global cultural systems, e.g., East Asian vs. Western European cultures, have demonstrated strong differences between adolescents' self-reports about their relation to their parents. First, it was obvious that such interactions differed significantly between East Asian and European adolescents. While East Asian adolescents referred much more frequently to conformity demands than did European adolescents, they also reported more supportive parental behavior, more giving in on their own part and a more harmonious relation with their parents. In line with Hofstede's (1980) results on value orientations, East Asian cultures were a priori considered to be collectivistic and Western European cultures to be individualistic cultures. Here, group orientation is used as a basic criterion for classification. Our empirical data support this classification of cultures.

The empirical data show that cultural groups differ with respect to single variables measuring parent-child relations. They also differ with respect to the interrelations between certain variables; thus, demonstrating functional differences of certain socialization conditions for parent-child relations. For example in the Asian as compared to the European samples, parental control is positively related to highly child-oriented behavior. In collectivistic, and especially traditional, cultures, both kinds of behavior are highly valued -- obedience demands and conformity to social norms and to authorities, on the one hand, and emotional support of members of the in-group, on the other hand. This is in line with other studies comparing East Asian and Western European patterns of socialization and development (e.g., Kornadt et al., 1991). In a collectivistic context, parental control obviously has a different meaning than in an individualistic one. Parental control is accepted by adolescents as part of a child-oriented supportive socialization context. Certain ("objective") socialization conditions like a specific kind of parental behavior, therefore, can be experienced very differently depending on the cultural context of socialization which transmits a certain culture-specific meaning. In an individualistic context of highly modernized societies (such as the United States or Germany), parental control is perceived by adolescents as constraint; in a traditional collectivistic context, the same kind of parental behavior is experienced by adolescents as support. However, in a period of transition to modernization and to individualistic value orientation, this may change. Social change and modernization obviously have an impact on the kind of socialization and more specifically on the meaning of parental control for adolescents. Pettengill and Rohner (1985) have demonstrated that Korean adolescents growing up in Korea as compared to Korean adolescents growing up in the United States 
perceive of parental control as an indicator of emotional support. This perception presumably is prevalent in collectivistic cultures as long as values of social connectedness and interdependence are more highly valued than individuality and independence.

Therefore, cultural contexts cannot only be differentiated according to values of individualism and collectivism. A further differentiation between cultural contexts with respect to their confrontation with modernity and individualism seems necessary. In line with this reasoning, our data clearly demonstrate that one cannot simply generalize about "the" East Asian and "the" European or about collectivistic and individualistic cultures. Significant differences in socialization patterns exist among the East Asian (or collectivistic) samples, on the one hand, and the European (or individualistic) samples, on the other hand.

For some parent-child variables, adolescents from Hindu-Buddhist cultures (Balinese and Japanese) were quite similar; for other variables, adolescents from traditional cultures (Balinese and Batak) were similiar and adolescents from modem cultures (Japanese and European) were similar. In collectivistic as compared to individualistic cultures, there were not only more parental conformity and obedience demands, especially in peer situations; but also more supportive parental behavior, mutual understanding and harmonious relations between adolescents and their parents. Adolescents from traditional (Bali and Batak) as compared to modern (Japan, Germany, and Scotland) societies also differed with respect to these variables. Furthermore, differences occurred here with respect to adolescents' feelings of security.

These results caution against using a simple one-dimensional concept of collectivism-individualism or traditionality-modernity when comparing the socialization of adolescents from different cultures and societies. Schwartz (1990) has warned against conceiving of individualism-collectivism as a one-dimensional variable. Any global distinction between cultures, cultural values, and cultural socialization should take into account the fact that each culture is unique and has its own history and is part of a specific societal and economic system. Furthermore, it can be assumed that cultural, societal and economic factors are interrelated on several different levels of the macro, meso, and micro systems which may result in culture-specific values or meanings which, in turn, affect the socialization conditions. Of course, this view could lead to the conclusion that crosscultural comparisons and an etic perspective are superfluous. On the contrary, cross-cultural studies are necessary, but should be combined with culture-specific and intra-cultural comparisons to avoid simple generalizations.

\subsection{Intra-Cultural Comparisons}

Intra-cultural comparisons allow one to move away from one-dimensional crosscultural analyses and to take into account intra-cultural contexts, e.g., ethnic and 
religious differences. In general, and also with respect to our data on parent-child relations, Batak and Balinese adolescents are relatively more similar than different, both following the Indonesian-Malaysian cultural tradition (Geertz, 1961; Magnis-Suseno, 1989; Pidada, 1993). However, even a comparison of Balinese and Batak samples may demonstrate how useful it can be to study intra-cultural variations. According to our data, the Balinese as compared to the Batak adolescents experience more control on the part of their parents. The Batak are growing up in a changing and modernizing environment and they are socialized in a Christian religious tradition which confronts them with different expectations and options. In contrast, Balinese adolescents are growing up in a more traditional context and the very different religious environment of Hindu culture. In the Christian religion, individual responsibility is valued; while in the Hindu culture, the individual person is first of all a part of the cultural system which he or she has to serve by fulfilling highly specified and regulated assigned duties. Thus, parental control is more highly valued; it is practiced more often and at the same time, readily accepted by Balinese adolescents.

A more extensive study comparing Balinese and Batak socialization may thus profit from focusing on differences related to religious values and on the transition to modernity. This approach allows one not only to differentiate between different aspects of South East Asian cultural contexts, but also to grasp the possible effects of modernization and individualization on socialization processes, e.g., parent-child relations. Modernization presumably follows culture-specific patterns. Therefore, it seems fruitful to study the culture-specific socialization of adolescents in transition to modernity and adolescents' coping with the developmental tasks of modern societies.

The Japanese case demonstrates clearly that modernization does not mean necessarily adopting individualistic values. This reminds us of the classical studies by Bellah (1971) and Bendix (1966/67) which demonstrate that the traditional values of Japan (e.g., Confucian ethics) have contributed significantly to Japan's rapid transition to modernity. Empirical studies have shown that these are still coexisting together with individualistic value orientations (cf., Trommsdorff, 1983; 1992; Trommsdorff, Suzuki, \& Sazaki, 1987). Our comparison between adolescents from traditional and modern societies gives some insight into problems related to development in modern societies. For instance, some aspects of adolescents' relations with their parents in conflict situations, such as tendencies towards alienation, occur more for adolescents from a modern than for those from a traditional cultural environment. This can be seen in less conforming behavior and adolescents' emotional experience of less security. Thus, adolescents from modern societies (Japan and Europe) prefer certain individualistic behaviors, such as resisting conformity demands while, at the same time, the developmental task of achieving autonomy may induce inner conflicts, especially when the cultural context is more socially oriented than in Japan. These conflicts are resolved during development in context. So far, it seems that Japanese ado- 
lescents only adopt individualistic values temporarily. When entering the stage of adulthood and employment, they adopt traditonal values again. This must, however, be studied empirically and longitudinally in order to understand the processes of social change and their relation to socialization and individual development.

Though strong differences exist between Asian and European adolescents' socialization experiences, one cannot neglect the intra-cultural differences within East Asian and Western, collectivistic and individualistic, traditional and modern, and Hinduistic/Buddhist and Christian cultures. Therefore, one cannot simply draw generalized conclusions about the relation between a certain cultural context and individual socialization. The complex variable "culture" needs to be differentiated (Whiting, 1976). Intra-cultural comparisons are necessary in order to specify the relations between cultural context and the various phenomena of socialization. Such intra-cultural comparisons should complement inter-cultural comparisons to gain a better understanding of individual development in context.

Again, intra-cultural comparisons allow one to become aware of other relevant dimensions of culture. For example, with respect to some aspects of socialization, Japanese adolescents differed from both their East Asian and Western European peers (e.g., receiving a higher degree of support by their parents during a conflict). With regard to other aspects, they differed from their East Asian peers, but not markedly from their European peers (e.g., when showing less cooperation with their parents and experiencing a low feeling of security). This may demonstrate that multiple cultural contexts are interacting during the socialization of children and adolescents. Japanese adolescents are socialized in a group-oriented, collectivistic society, while, at the same time, they share experiences of their age-mates from individualistic cultural contexts. In this way, they are growing up in a highly modernized society which has still preserved many aspects of the traditional collectivistic cultural history.

Here, the questions arise of how ongoing social change will affect the socialization conditions of the next generation and how adolescents will affect social changes on account of changing relations to their parents.

\subsection{Conclusions and Outlook}

1. Some of the cultural differences observed in our study can be attributed to differences in modernity versus traditionalism, in individualism versus collectivism, and in religion. It has been shown that one-dimensional differentiations alone do not adequately account for cultural differences in socialization conditions and intergenerational relations as perceived by adolescents. Further studies are needed to carry out systematic comparisons between these different aspects of cultural contexts which are partly confounded in our samples. 
2. How are these different cultural contexts related to processes of social change? The strong control and simultaneously more supportive empathic child-oriented parental behavior in traditional as compared to modern societies raises the questions of whether parent-child relations are closer in traditional than in modern societies and whether adolescent development is more focused on attaining and promoting the values and social roles of the parents. Adolescents from traditional as compared to modern cultural contexts see less reason to distance themselves from their parents and yield less to social change. Furthermore, these adolescents accept their parents' demands and consider these as part of their parents' supportive behavior. This presumably is the basis for the internalization of the parents' value system and for the continuation of traditional beliefs; here intergenerational conflicts are rare or they are easily resolved.

Of course, it is not clear in which direction this process may operate: whether traditional values foster this kind of restrictive and simultaneously mutually supportive empathic intergenerational relationship or whether this kind of close relationship supports the continuity of traditional values and restriction from social and economic change.

3. This question can be further elaborated when focusing on the differences between individualistic and collectivistic societies. The overall results have demonstrated a strong tendency towards both harmony in parent-child relations and adolescent conformity in collectivistic as compared to individualistic societies. Intergenerational relations in individualistic societies are characterized by more conflict than in collectivistic societies (Trommsdorff, 1993c). It seems that individualistic orientations and pursuing one's own interests give rise to conflicts while, at the same time, they may be part of social change. Harmonious intergenerational relations, on the other hand, do not seem to hinder economic development or change as can be seen from the Japanese sample. Economic development need not be based on individualistic values or conflicting social relations. On the contrary, social orientation and supportive intergenerational relations may be a stabilizing factor in the process of economic and technological change.

4. Finally, the differences between Christian and Buddhist-Hindu cultures indicate a dimension which characterizes intergenerational relations and adolescent development from another perspective. Here, it becomes obvious that the developmental task of identify formation is defined differently in the two cultural contexts. Independence is highly valued in the Christian cultures and interdependence and conformity are highly preferred in the Buddhist-Hindu cultures. Possible relations between these value orientations and the tendency to promote social change need further empirical clarification. 
5. To conclude, the starting point of the present study was to describe aspects of adolescents' socialization in different cultural contexts by focusing on possible differences in the relation between person and environment. The empirical data demonstrate that in Eastern and Western, collectivistic and individualistic, and traditional and modern cultural contexts significant differences in adolescents' interactions with their parents exist with respect to the focus of social-environment relations. For example, in collectivistic cultures, adolescents are more oriented towards complying with parental demands, while simultaneously the establishment of positive interpersonal relations suffers. This is in line with theoretical notions on the development of an interdependent self (cf., Markus \& Kitayama, 1991). In individualistic cultures, adolescents are more oriented towards distancing themselves from parental demands, while, at the same time, the emotional quality of harmonious interpersonal relations suffers. This is in line with notions on the development of an independent self.

Such culture-specific developmental paths of person-environment relations can also be observed in the cultural differences in control orientation. The development of an interdependent self should be related to accommodative (or "secondary") control, while the development of an independent self should be more related to assimilative (or "primary") control (cf., Rothbaum, Weisz \& Snyder, 1982; Trommsdorff, 1989; 1994). Though a certain balance between "primary" and "secondary" control seems to be a successful strategy for problem solving, cultural differences in giving priority to either orientation may exist. In individualistic cultures, adolescents are more likely to prefer "primary" control, i.e., to prefer achieving autonomy of self and changing the environment, rather than changing themselves. In collectivistic cultures, adolescents are more likely to prefer "secondary" control, i.e., to adapt to the given circumstances and accommodate accordingly. This difference in control orientation may be a major reason for less conflict in parent-child relations and for a more pronounced social orientation in this cultural context. It seems that "secondary" control orientation fosters a strong alignment of the self with his/her social environment, while "primary" control orientation promotes differentiation between the self and the environment, e.g., adolescents and their parents.

Accordingly, the specific person-environment relation and respective value orientations are a basis for certain developmental processes and for the person's active participation in social changes. Empirical data on how culture-specific differences in socialization conditions and person-environment relations are related to aspects of social change should be studied in more detail by systematically comparing adolescents from different cultural contexts over time. 


\section{Author Note}

This study represents parts of a larger cross-cultural study which was financed by the Volkswagen Foundation (e.g., Kornadt et al., 1991). I thank Bertrand Lisbach for his careful work on the data analyses and Wolfgang Friedlmeier for his critical comments on an earlier version of this article.

\section{References}

Azuma, H. (1986). Child development and education in Japan. New York: Freeman.

Bellah, R. N. (1971). Continuity and change in Japanese society. In R. Barber \& A. Inkeles (Eds.), Stability and social change. Boston: Little Brown.

Bendix, R. (1966/67). Tradition and modernity reconsidered. Comparative Studies in Society and History, 9, 292-346.

Bronfenbrenner, U. (1979). The ecology of human development. Experiments by nature and design. Cambridge: Harvard University Press.

Bronfenbrenner, U., Kessel, F., Kessen, \& White, S. (1986). Toward a critical social history of developmental psychology. A propaedeutic discussion. American Psychologist, 41, 1218-1230.

Elder, G. (1974). Children of the great depression. Social change in life experience. Chicago: University of Chicago Press.

Geertz, H. (1961). The Javanese family. Glencoe: The Free Press.

Geertz, L. (1973). The interpretation of cultures. New York: Basic Books.

Gergen, K. J. (1985). The social constructionist movement in modern psychology. American Psychologist, 40, 265-275.

Goodnow, J. J., Knight, R., \& Cashmore, J. (1986). Adult social cognition: Implications of parents' ideas for approaches to development. In M. Perlmutter (Ed.), Cognitive perspectives on children's social and behavioral development. Hillsdale: Erlbaum.

Hayashi, C., \& Suzuki, T. (1990). Beyond Japanese social values: Trend and cross-national perspectives. Tokyo: The Institute of Statistical Mathematics.

Hofstede, G. (1980). Culture's consequences: International differences in work-related values. London: Sage.

Hutschemaekers, G. J. M. (1990). The historical-contextualist approach: The case of neurotic anxiety. In J. R. van de Vijver \& G. J. M. Hutschemaekers (Eds.), The investigation of culture: Current issues in cultural psychlolgy. Tilburg: Tilburg University Press.

Johnson, F. (1985). The western concept of the self. In A. J. Marsella, G. de Vos, \& F. L. K. Hsu (Eds.), Culture and self: Asian and Western perspectives. New York: Tavistock.

Kornadt, H.-J. (1989). Frühe Mutter-Kind-Beziehungen im Kulturvergleich. In G. Trommsdorff (Ed.), Sozialisation im Kulturvergleich. Stuttgart: Enke.

Kornadt, H.-J. (1993). Kulturvergleichende Motivationsforschung. In A. Thomas (Ed.), Einführung in die kulturvergleichende Psychologie. Göttingen: Hogrefe.

Kornadt, H.-J., Hayashi, T., Tachibana, Y., Trommsdorff, G., \& Yamauchi, H. (1991). Aggressiveness and its developmental conditions in five cultures. In S. Iwawaki, Y. Kashima, \& K. Leung (Eds.), Innovations in cross-cultural psychology. 
Kornadt, H.-J. \& Trommsdorff, G. (1993). Deutsch-japanische Begegnungen in den Sazialwissenschaften. Universitătsverlag Konstanz.

Kornadt, H.-J. \& Trommsdorff, G. (1990). Naive Erziehungstheorien japanischer Mütter - deutsch-japanischer Kulturvergleich. Zeitschrift für Sozialisationsforschung und Erziehungssoziologie, 2, 357-376.

Lerner, R. M., \& Kauffman, M. B. (1985). The context of development in contextualism. Developmental Review, 5, 309-333.

Magnis-Suseno, F. (1989). Neue Schwingen far Garuda. Indonesien zwischen Tradition und Moderne. München: Kindt.

Markus, H. R., \& Kitayama, S. (1991). Culture and the self: Implications for cognition, emotion, and motivation. Psychological Review, 98, 224-253.

Marsella, A. J., DeVos, G., \& Hsu, F. L. K. (Eds.) (1985). Culture and self: Asian and Western perspectives. New York: Tavistock.

Moscovici, S. (1982). The coming era of representations. In J. P. Codol \& J. Leyens (Eds.), Cognitive analysis of social behavior. The Hague: Nijhoff.

Moscovici, S. (1984). The phenomenon of social representation. In R. M. Farr \& S. Moscovici (Eds.), Social representation. Cambridge: Cambridge University Press.

Munroe, R. L., \& Munroe, R. H. (1975). Cross-cultural human development. Monterey: Brooks/Cole.

Pettengill, S. M. \& Rohner, R. P. (1985). Korean-American adolescents perceptions of control,parental acceptance-rejection and parental-adolescent conflict. In I. Reyers-Lagunes \& Y. H. Poortinga (Eds.), From a different perspective: Studies of behavior across cultures. Liss: Swets \& Zeitlinger.

Pidada, S. U. (1993). Mütterliche Erziehungsbedingungen für prosoziale Motivation. Unveröffentlichte Dissertation. Saarbrücken: Universităt des Saarlandes.

Rohner, R. (1975). They love me, they love me not: $A$ worldwide study of the effects of parental acceptance and rejection. Beverley Hills: Sage.

Rothbaum, F., Weisz, J. R., \& Snyder, S. S. (1982). Changing the world and changing the self: A twoprocess model of perceived control. Journal of Personality and Social Psychology, 42, 5-37.

Schwartz, S. H. (1990). Individualism-collectivism: Critique and proposed refinements. Journal of Cross-Cultural Psychology, 21, 139-157.

Segall, M. H. (1993). Cultural psychology: Reactions to some claims and assertions of dubious validity. Cross-Cultural Psychology Bulletin, 27, 2-4.

Shweder, R. A. (1990). Cultural psychology - what is it? In J. W. Stigler, R. A. Shweder, \& G. Herdt (Eds.), Cultural psychology: Essays on comparative human development. Cambridge: Cambridge University Press.

Sigel, I. E. (Ed.) (1985). Parental belief systems: The psychological consequences for children. Hillsdale: Erlbaum.

Smith, M. B. (1978). Perspectives on selfhood. American Psychologist, 33, 1053-1063.

Spence, J. T. (1987). Centrifugal versus centripetal tendencies in psychology: Will the center hold? American Psychologist, 12, 1052-1054.

Stevenson, H., Azuma, H., \& Hakuta, K. (Eds.) (1986). Child development and education in Japan. Oxford: Freeman.

Super, C., \& Harkness, S. (1986). The developmental niche: A conceptualization at the interface of child and culture. International Journal of Behavioral Development, 9, 545-569.

Triandis, H. C. (1985). Collectivism vs. individualism: A reconceptualization of a basic concept in cross-cultural psychology. In C. Bagley, \& G. K. Verina (Eds.), Personality, cognition, and value: Cross-cultural perspectives of childhood and adolescence. London: Macmillan. 
Triandis, H. C. (1989). The self and social behavior in differing cultural contexts. Psychological Review, $96,506-520$.

Triandis, H. C. (1990). Cross-cultural studies of individualism and collectivism. In J. J. Berman (Ed.), Nebraska Symposium on Motivation, 1989: Cross-cultural perspectives. Lincoln: University of Nebraska Press.

Trommsdorf, G. (1983). Value change in Japan. International Journal of Intercultural Relations, 7 , $337-360$.

Trommsdorf, G. (1984). Familiale Sozialisation im Kulturvergleich: Japan und Deutschland. Zeitschrift for Sozialisationsforschung und Erziehungssoziologie, 4, 79-97.

Trommsdorf, G. (1989). Sozialisation und Werthaltungen im Kulturvergleich. In G. Trommsidorff (Ed.), Sozialisation im Kulturvergleich. Stuttgart: Enke Verlag.

Trommsdorff, G. (1992). Values and social orientations of Japanese youth in intercultural comparison. In S. Formanek \& S. Linhart (Eds.), Japanese biographies: Life histories, life cycles, life stages. Wien: Verlag der osterreichischen Akademie der Wissenschaften.

Trommsdorff, G. (1993a). Besonderheiten sozialen Handelns in Japan. Fragen an die sozialwissenschaftliche Forschung. In H.-J. Kornadt \& G. Trommsdorff (Eds.), Deutsch-japanische Begegnumgen in den Sozialwissenschaften. Konstanz: Universitătsverlag Konstanz.

Trommsdorff, G. (1993b). Entwicklung im Kulturvergleich. In A. Thomas (Ed.), Einfuhrung in die kulturvergleichende Psychologie. Göttingen: Hogrefe.

Trommsdorff, G. (1993c). Geschlechtsdifferenzen von Generationenbeziehungen im interkulturellen Vergleich: Eine entwicklungspsychologische Analyse. In K. Lüscher \& F. Schultheis (Eds.), Generationenbeziehungen in 'postmodern' Gesellschaften. Konstanz: Universitátsverlag Konstanz.

Trommsdorf, G. (1994). Psychologische Probleme bei den Transformationsprozessen in Ostdeutschland. In G. Trommsdorff (Ed.), Psychologische Aspekte des sozio-politischen Wandels in Ostdeutschland. Berlin: De Gruyter.

Trommsdorf, G. \& Friedlmeier, W. (1993). Control behavior and responsiveness in Japanese and German mothers. Early Development and Parenting, 2, 65-78.

Trommsdorf, G., Suzuki, T., \& Sasaki, M. (1987). Soziale Ungleichheiten in Japan und der Bundesrepublik Deutschland. Kolner Zeitschriff fur Soziologie und Sozialpsychologie, 39, 471-495.

Valsiner, J. (1987). Culture and the development of children's action: A cultural-historical theory of the developmental psychology. Chichester: Wiley.

Valsiner, J. (1989). General conclusion. Towards culture-inclusive developmental psychology: Overcoming epistemiological obstacles. In J. Valsiner (Ed.), Child development in cultural context. Toronto: Hogrefe \& Huber.

Vijver, F. J. R. van de, \& Hutschemaekers, G. J. M. (Eds.) (1990). The investigation of culture: Current issues in cultural psychology. Tilburg: Tilburg University Press.

Waterman, A. S. (1981). Individualism and interdependence. American Psychologist, 36, 762773.

Weber, M. (1920). Die protestantische Ethik und der "Geist" des Kapitalismus. Tubingen: J. C. B. Mohr.

Whiting, B. B. (1976). The problem of the packaged variable. In K. F. Riegel \& J. A. Meacham (Eds.), The developing individual in a changing world, Vol. 1. The Hague: Mouton. 